\title{
Enhancement of a modified Mediterranean-style, low glycemic load diet with specific phytochemicals improves cardiometabolic risk factors in subjects with metabolic syndrome and hypercholesterolemia in a randomized trial
}

\author{
Robert H Lerman*, Deanna M Minich, Gary Darland, Joseph J Lamb, \\ Barbara Schiltz, John G Babish, Jeffrey S Bland and Matthew L Tripp
}

Address: Functional Medicine Research Center, MetaProteomics, LLC, 9770 44th Ave. NW, Ste 100, Gig Harbor, WA 98332, USA

Email: Robert H Lerman* - BobLerman@metagenics.com; Deanna M Minich - DeannaMinich@metagenics.com;

Gary Darland - GaryDarland@metagenics.com; Joseph J Lamb - JosephLamb@metagenics.com; Barbara Schiltz - nutrbarb@gmail.com;

John G Babish - jgb7@cornell.edu; Jeffrey S Bland - JeffBland@metagenics.com; Matthew L Tripp - MatthewTripp@metagenics.com

* Corresponding author

Published: 4 November 2008

Nutrition \& Metabolism 2008, 5:29 doi:10.1 186/1743-7075-5-29
Received: 9 July 2008

Accepted: 4 November 2008

This article is available from: http://www.nutritionandmetabolism.com/content/5/I/29

(C) 2008 Lerman et al; licensee BioMed Central Ltd.

This is an Open Access article distributed under the terms of the Creative Commons Attribution License (http://creativecommons.org/licenses/by/2.0), which permits unrestricted use, distribution, and reproduction in any medium, provided the original work is properly cited.

\begin{abstract}
Background: As the worldwide dietary pattern becomes more westernized, the metabolic syndrome is reaching epidemic proportions. Lifestyle modifications including diet and exercise are recommended as first-line intervention for treating metabolic syndrome. Previously, we reported that a modified Mediterranean-style, low glycemic load diet with soy protein and phytosterols had a more favorable impact than the American Heart Association Step I diet on cardiovascular disease (CVD) risk factors. Subsequently, we screened for phytochemicals with a history of safe use that were capable of increasing insulin sensitivity through modulation of protein kinases, and identified hops rho iso-alpha acid and acacia proanthocyanidins. The objective of this study was to investigate whether enhancement of a modified Mediterranean-style, low glycemic load diet (MED) with specific phytochemicals (soy protein, phytosterols, rho iso-alpha acids and proanthocyanidins; PED) could improve cardiometabolic risk factors in subjects with metabolic syndrome and hypercholesterolemia.
\end{abstract}

Methods: Forty-nine subjects with metabolic syndrome and hypercholesterolemia, aged 25-80, entered a randomized, 2-arm, I2-week intervention trial; 23 randomized to the MED arm; 26 to the PED arm. Forty-four subjects completed at least 8 weeks [MED $(n=19)$; PED $(n=25)]$. All subjects were instructed to follow the same aerobic exercise program. Three-day diet diaries and 7-day exercise diaries were assessed at each visit. Fasting blood samples were collected at baseline, 8 and 12 weeks for analysis.

Results: Both arms experienced equal weight loss (MED: $-5.7 \mathrm{~kg}$; PED: $-5.9 \mathrm{~kg}$ ). However, at 12 weeks, the PED arm experienced greater reductions $(P<0.05)$ in cholesterol, non-HDL cholesterol, triglycerides $(T G)$, cholesterol/HDL and TG/ HDL compared with the MED arm. Only the PED arm experienced increased HDL $(P<0.05)$ and decreased TG/HDL $(P<0.01)$, and continued reduction in apo B/apo A-I from 8 to 12 weeks. Furthermore, 43\% of PED subjects vs. only $22 \%$ of MED subjects had net resolution of metabolic syndrome. The Framingham 10-year CVD risk score decreased by $5.6 \%$ in the PED arm $(P<$ $0.01)$ and $2.9 \%$ in the MED arm $(P<0.05)$.

Conclusion: These results demonstrate that specific phytochemical supplementation increased the effectiveness of the modified Mediterranean-style low glycemic load dietary program on variables associated with metabolic syndrome and CVD. 


\section{Background}

Overconsumption of a maladaptive, westernized diet consisting of foods that are calorie-dense, nutritionally-poor, phytochemical-depleted, highly processed and rapidly absorbable has been shown to increase systemic inflammation and reduce insulin sensitivity [1-3]. With chronic ingestion, this dietary pattern often results in metabolic syndrome (MetS), a physiologic state encompassing a cluster of metabolic abnormalities, including dyslipidemia, central obesity, hypertension, and glucose intolerance. These are all independent risk factors for the development of type 2 diabetes and/or cardiovascular disease (CVD) [4,5]. The NHANES 1999-2000 estimated the prevalence of MetS in the US at an unadjusted $34.5 \%$ or approximately 69 million persons [6]. As worldwide food consumption patterns shift to the aforementioned dietary pattern, MetS is becoming a significant burden in developing nations and global prevalence is growing $[7,8]$.

It is widely viewed that MetS results from an increasing, perpetual state of whole body insulin resistance, which is strongly associated with dietary carbohydrate [9-11] and saturated fat [12], leading to high serum triglycerides (TG) and visceral adiposity [13-15]. Acute infusion of free fatty acids leads to the accumulation of TG in skeletal muscle and evokes whole body insulin resistance with the same temporal pattern [16-19]. Metabolites of lipid metabolism such as diacylglycerol have been shown to directly induce insulin resistance by chronically activating protein kinase C (PKC). PKC activation terminates insulin signaling, preventing crucial tyrosine phosphorylation by the insulin receptor, leading to impaired insulin signaling [14]. MetS is also associated with a state of chronic inflammation. Adipocyte leakage has recently been shown to result in the recruitment of macrophages, which envelope excess lipids, form foam cells, and release inflammatory cytokines, setting up a state of systemic, chronic inflammation $[20,21]$. These adipokines lead to the systemic activation of several protein kinases involved in inflammatory signal transduction, including phosphoinositide3 kinase (PI3K), glycogen synthase kinase (GSK-3) and PKC that singly or in concert cause insulin resistance in skeletal muscle and adipose tissue [22-24]. Hence, therapies which reduce circulating lipids and reduce systemic inflammation have shown promise in the treatment of insulin resistance and MetS.

Lifestyle modifications including diet and exercise are recommended as first-line intervention for treating insulin resistance and MetS by the National Cholesterol Education Program (NCEP) and American Heart Association (AHA). The Mediterranean-style diet, high in plant foods and monounsaturated fatty acids and low in processed foods and refined carbohydrates, has been shown to reduce CVD risk factors [25-28] and inflammatory burden associated with MetS etiology [29]. Pharmacologic treatment is considered appropriate if the individual is refractory to a lifestyle approach $[30,31]$. A recent review of the literature reveals that both intensive lifestyle modifications and drugs such as rimonabant or rosiglitazone may reduce the prevalence of MetS in $25-33 \%$ of patients [32]. While new pharmacologic approaches to MetS are under development [7], relying on drug therapy for an epidemic caused by a maladaptive diet is not as rational as realigning dietary habits [33]. These findings suggest that new lifestyle modification approaches in the treatment of MetS and its complications should be important public health priorities.

Advancing knowledge in inflammation and insulin signaling suggest that reversing the chronic imbalances of these downstream kinases provides a promising and logical strategy for reducing insulin resistance and the metabolic abnormalities of MetS. Inhibition of downstream kinases could be accomplished by using pharmaceuticals such as sunitinib and imatinib (multi-target protein kinases drugs), approved to treat cancers but which may also cause remission of diabetes [34]. However, several dietary phytochemicals, such as genistein and curcumin, have been shown to be protein kinase inhibitors $[35,36]$. A recent study showed that combining additional dietary polyphenols with a Mediterranean diet could provide synergistic effects and positively impact postprandial dysmetabolism [33]. As such, an important aspect to consider in dietary recommendations for MetS is the incorporation of diverse, targeted biologically-active phytochemicals to address the multiple underlying mechanisms of MetS. In a previous study [37], we reported that the addition of soy protein and phytosterols to a Mediterranean-style, low glycemic load diet had a more favorable impact than the AHA Step 1 diet on cholesterol/HDL and TG/HDL, blood pressure (BP), and Framingham 10-year CVD risk score for coronary heart disease in overweight, postmenopausal, hypercholesterolemic women.

With the finding that soy protein and phytosterols plus a Mediterranean-style diet could favorably affect the TG/ HDL, an indicator of MetS, we initiated a screening program to identify additional structurally diverse phytochemicals capable of increasing insulin sensitivity through the modulation of downstream kinases. We screened 203 botanical products in 3T3-L1 adipocytes and identified novel substituted 1,3-cyclopentadiones as well as a number of proanthocyanidin extracts with adipogenic and anti-inflammatory activity. One of the substituted 1, 3-cyclopentadiones was tho iso-alpha acids (RIAA) derived from hops (Humulus lupulus). RIAA have been used as bitter flavoring agents in beer for decades. We found RIAA dose dependently inhibited GSK-3, PI3K, and PKC $\beta$ in cell free kinase assays (manuscript in prepara- 
tion). Another bioactive material identified by our screen was the proanthocyanidin-rich extract (PAC) of Acacia nilotica. In addition to inhibiting GSK-3, PI3K, and PKC, it also inhibited IKK $\beta$ in a dose-dependent manner (manuscript in preparation). At 5:1 (RIAA:PAC), the greatest efficacy in reducing glucose and insulin in the $d b / d b$ mouse model was observed (manuscript in preparation). Furthermore, in an unpublished human pilot study, MetS subjects who consumed a combination of RIAA and PAC showed greater lowering of fasting LDL, TG, and TG/HDL than the placebo group.

The objective of this study was to investigate whether by enhancing a modified Mediterranean-style, low glycemic load diet with specific phytochemical supplementation we could improve cardiometabolic outcomes in subjects with MetS. Targeted supplementation included soy protein, phytosterols, hops RIAA and acacia PAC. The same diet was used in both arms and incorporated a spectrum of unprocessed, modified Mediterranean-style foods with an overall glycemic load less than 65 .

\section{Methods \\ Subjects}

Men and women between the ages of 25 to 80 years with MetS and hypercholesterolemia were recruited into this study. Inclusion criteria included body mass index (BMI) $\geq 27 \mathrm{~kg} / \mathrm{m}^{2}, \mathrm{TG} \geq 1.70 \mathrm{mmol} / \mathrm{L}$ and $<4.52 \mathrm{mmol} / \mathrm{L}$, LDL $\geq 3.37 \mathrm{mmol} / \mathrm{L}$, and at least 2 of the following 4 criteria: (i) waist circumference $>88 \mathrm{~cm}$ (women) and $>102 \mathrm{~cm}$ (men); (ii) $\mathrm{HDL}<1.30 \mathrm{mmol} / \mathrm{L}$ (women), and $<1.04$ $\mathrm{mmol} / \mathrm{L}$ (men); (iii) BP $\geq 130 / 85 \mathrm{~mm} \mathrm{Hg}$ and $<155 / 95$ $\mathrm{mm} \mathrm{Hg}$ or diagnosed hypertension on medication; and (iv) fasting glucose $\geq 5.55 \mathrm{mmol} / \mathrm{L}$ and $\leq 7.00 \mathrm{mmol} / \mathrm{L}$. Initial screening of subjects' serum lipids and glucose was performed using an in-office device (Cholestech LDX ${ }^{\circledast}$ System). Eligible subjects were further screened with complete metabolic profile and complete blood count. Some key exclusion criteria included involvement in a weight loss program leading to $10 \%$ or greater body weight loss over the preceding 6 weeks; use of blood glucose or cholesterol lowering medications or supplements, corticosteroid use in the preceding 12 weeks; NSAID use $\geq 3$ days/ week in the preceding 4 weeks; or a history of chronic illness. This study was approved by the Copernicus Group Independent Review Board and was conducted based on good clinical practice guidelines. Informed written consent was obtained from each participant before enrollment in the study.

\section{Study design}

This study was a randomized, 12-week, open-label, 2-arm trial conducted at the Functional Medicine Research Center in Gig Harbor, WA from June 15, 2006 through November 20, 2006 (Fig. 1). Subjects who satisfied the inclusion criteria were randomized to 1 of 2 arms using a commercial software program (Microsoft Excel $^{\oplus}$ 2003; Microsoft); subjects were stratified by sex. Participants from both arms were instructed to follow a modified Mediterranean-style, low glycemic load diet (MED) and were provided with dietary guidelines, including a list of allowable foods, suggested serving sizes and recipes (see additional file 1: List of Permitted Foods and Beverages, Serving Sizes and Recipe). Subjects were asked to consume the diet until satisfied.

Modified Mediterranean-style low glycemic load diet (MED) The rationale for defining this dietary program as "modified Mediterranean-style, low glycemic load" is that it includes a variety of low glycemic phytochemically-rich foods. Not all Mediterranean-style diets are low in glycemic load [38], and not all low glycemic load diets are phytochemically-diverse; thus, we chose to leverage the benefits of both by combining them together.

Specifically, the diet used in this study is distinguishable from the classic Mediterranean diet in that it is limited in the number of servings of alcohol and, in particular, whole grain. Alcohol intake was kept to a minimum: an optional 1 glass of red wine ( $4 \mathrm{oz}$ ) daily for all subjects. In the Mediterranean diet, several (typically 6 or more) servings of grain are often advocated; however, based on the available literature and our experience with this dietary program in the past decade, we decided to limit whole grains to 1 serving daily. Riccardi et al. [38] suggested that the standard Mediterranean diet may not be beneficial for individuals with insulin resistance due to the high carbohydrate content. Additionally, in our own use of this program, we found that reducing grain intake lowers cravings in many subjects. Moreover, Mediterranean-like food items such as pizza and hard toasted bread have been shown to have glycemic responses similar to white bread. Thus, one of the primary stipulations for foods in this dietary program was to ensure that all items included were low in glycemic load. The glycemic index of foods most commonly eaten was $\leq 55$, with occasional selection (no more than 1 serving daily) from a small category of phytochemical-rich vegetables with a moderate glycemic index (55-70). This diet is also notable in that it omits all forms of sweeteners (natural and synthetic) except lowglycemic agave nectar syrup and stevia.

Phytochemical enriched diet (PED)

Subjects in the Phytochemical Enriched Diet (PED) arm additionally received (i) a combination of soy protein and plant sterols in a powdered beverage ( 2 servings/day, see additional file 2: Macronutrient profile of the soy and phytosterol-based powdered beverage) and (ii) a tablet containing RIAA from Humulus lupulus L. (RIAA magnesium salt) and PAC from Acacia nilotica bark (1 tablet, 2 


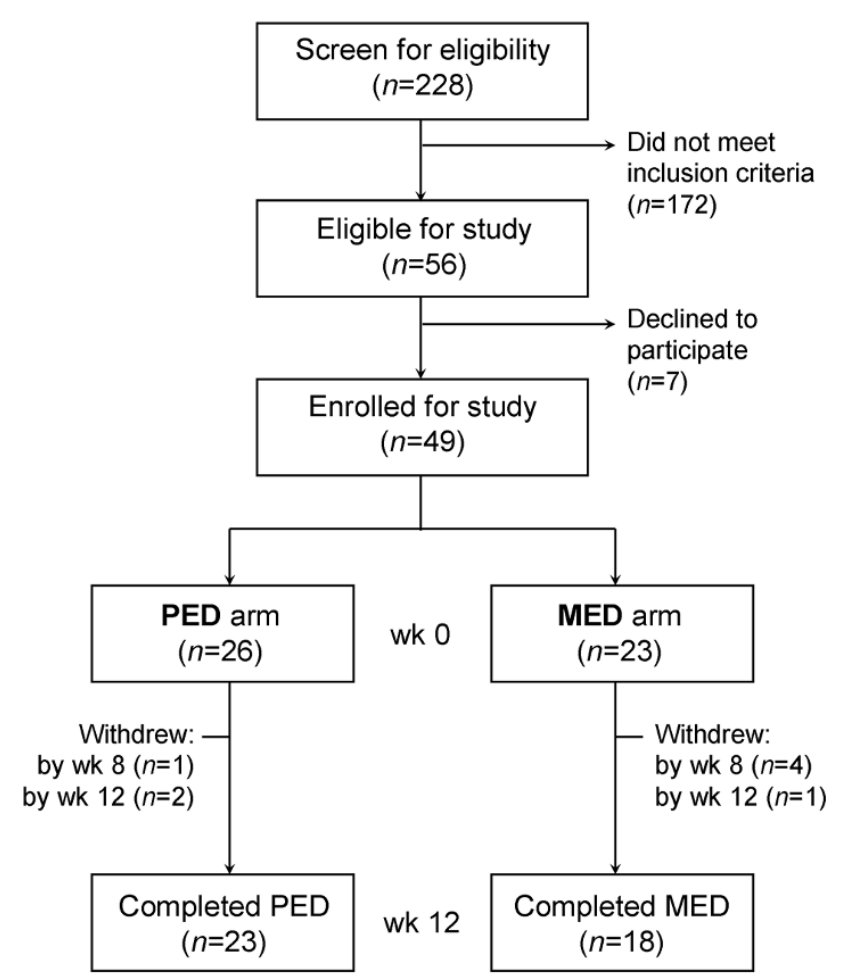

Figure I

Flow chart of participant enrollment and study design.

times daily). Two daily servings of the powdered beverage (UltraMeal Plus ${ }^{\circledR}$, Metagenics Inc.) provided $30 \mathrm{~g}$ of nonGMO soy protein (34 mg soy isoflavones) and $4 \mathrm{~g}$ of phytosterols (at least $40 \% \beta$-sitosterol). The tablet contained $150 \mathrm{mg}$ RIAA and $30 \mathrm{mg}$ PAC. At 2 daily, subjects ingested a total of $300 \mathrm{mg}$ RIAA and $60 \mathrm{mg}$ PAC. Subjects were instructed to return all unused beverage powder and tablets, and the percentage of the amount consumed was calculated to indicate compliance. Subjects in the MED arm received neither the powdered beverage nor tablets. All participants were counseled to eat 3 meals/day plus snacks and to eat until hunger was satisfied. With or without the powdered beverage, the diet was designed to provide a total glycemic load of not more than 65 . In addition to the diet, subjects in both arms were told to exercise aerobically, for a goal of 150 minutes/week, at 50-75\% of maximum heart rate. Individual and target heart rates were calculated for each subject, and instruction on monitoring heart rates was provided.

\section{Phytochemical tablet description}

RIAA from Humulus lupulus $\mathrm{L}$ ( $50 \mathrm{mg} /$ tablet)

For this study, a commercial preparation of the dried RIAA magnesium salt (Mg-RIAA) provided by John I. Haas (Yakima, WA) was used. As supplied, this material con- tained approximately 25\% inorganic salts, eg., $\mathrm{Mg}^{+2}, \mathrm{~K}^{+}$, and $\mathrm{SO}_{4}^{-2}, 5 \%$ low-molecular resin and $68 \%$ total RIAA. This RIAA fraction is a well-characterized mixture of related analogs and diastereomers (Fig. 2) with a ratio of cis to trans of $3: 1$ and the ratio of co- to n- of 1:2.2. The rationale for the magnesium salt form of the extract is that it provides a free flowing powder allowing for the blending and tablet manufacture of the finished product.

\section{PAC from Acacia nilotica bark (30 mg/tablet)}

Acacia PAC extract was provided by KDN-Vita International/Indfrag Ltd. Due to the manufacturing process, the extract has a great deal of chemical homogeneity. The chemical variation relates more to the level of polymerization (Fig. 2) than differences in the monomers, which are mostly catechins and gallates. Generally, an aqueous/ methanol acacia extract consists of approximately $16 \%$ small molecule catechins and gallates, 28\% oligomeric PAC and 56\% polymeric PAC.

\section{Measurements}

After the baseline visit, subjects returned at 2, 4, 8, and 12 weeks for follow-up visits. At each visit, 3-day diet diaries (including food choice, amount, time eaten) and 7-day exercise diaries (including form of exercise, intensity, duration) were evaluated and subjects were counseled on compliance to diet and exercise goals. Dietetic food models (Nasco) were used for accurate estimation of food intake. Data from 3-day diet diaries were analyzed using Genesis R\&D 6.30 (ESHA Research). Glycemic load was calculated as described previously [39]. Body weight and $\mathrm{BP}$ were measured at each visit. BP was measured with an automatic BP monitor (Model HEM-711, Omron Healthcare, Inc.). Waist circumference was measured at the narrowest point between the iliac crest and the lowest rib at baseline, at 8 weeks, and 12 weeks.

Subjects completed a Food Craving Inventory (Pennington Biomedical Research Center), a Medical Outcome Study Short Form 36 (a questionnaire to assess the quality of life) [40], and a satiety questionnaire at each visit. The Food Craving Inventory listed 28 different foods and instructed the subject to rate cravings to consume each particular food over the preceding month [41]. The questionnaire was scored according to groupings of foods in 4 subscales: high fats, sweets, carbohydrates/starches, and fast foods. A higher score indicated increased levels of craving. Satiety was assessed using a $10 \mathrm{~cm}$ visual analog scale in which subjects were asked to assess feelings of hunger since their last visit at three different times during the day; a higher score indicated more feelings of hunger. Individual scores were averaged for overall satiety per subject. Diet and exercise compliance were assessed at each visit by one of the investigators. The number of minutes of aerobic exercise was obtained from each subject's 7-day 
exercise diary. The Framingham 10-year CVD risk score was calculated as described previously [42] by using age and relevant laboratory and questionnaire data for every individual.

\section{Laboratory analyses}

Following an overnight fast, blood samples were collected from subjects at baseline, 8 weeks, and 12 weeks and stored at $-80^{\circ} \mathrm{C}$. Analysis of serum samples was conducted in batches and, except for lipoprotein subclass analysis, was performed by Laboratories Northwest. Glucose, lipids, and complete metabolic profiles of serum samples were assayed using a Vitros 950IRC analyzer (Ortho-Clinical Diagnostics). LDL was determined indirectly using the Friedewald formula: $\mathrm{LDL}=$ total cholesterol $-\mathrm{HDL}-\mathrm{TG} /$ 5 [43]. Non-HDL was determined by subtracting HDL from total cholesterol [44]. Apolipoproteins (apo) A-I and B were analyzed by turbidimetry using an Advia $1650^{\circledR}$ (Bayer Diagnostics). Lipoprotein subclass particle analysis was done with an automated NMR spectroscopic assay by LipoSciences, Inc. Insulin was determined by a chemiluminescent, immunometric assay using the DPC Immulite 2000 (Diagnostics Products Corporation). HbA1c was quantified on fresh blood samples by ion exchange HPLC (Bio-Rad Variant II). Complete blood count was done on fresh blood by standard laboratory methods.

\section{Statistical analysis}

Sample size was determined based on the results of an earlier study [37] in which a mean decrease of $0.62 \mathrm{mmol} / \mathrm{L}$ in LDL with the SD of $0.85 \mathrm{mmol} / \mathrm{L}$ was reported. Assuming a significance level of 0.05 with the power of $80 \%$, a sample size of 17 subjects per treatment group was needed. We recruited more than 34 subjects to account for possible attrition. The data were analyzed as follows: for each variable, changes from baseline to 8 weeks and 12 weeks were calculated for each treatment group. Baseline determinations were analyzed using 2-sided t-tests. Changes from baseline to 8 weeks and 12 weeks were analyzed separately for each arm using a priori one-sided paired t-test. To detect any treatment differences between the arms, one sided unpaired t-tests were used. Additional analyses adjusting for calorie intake change, carbohydrate intake change and body weight loss were performed by using General Linear Model. Two-sided Wilcoxon signedrank analysis was used to determine the significance of change in MetS score within arms. Missing values were not imputed for these analyses. Data were reported as means \pm SE and analyzed using SAS (software version 8.1, SAS Institute). The probability of a type I error was set at the nominal 5 percent level.

\section{Results \\ Subjects}

The characteristics of subjects at baseline are presented in Table 1. None of the subjects had been in a weight loss

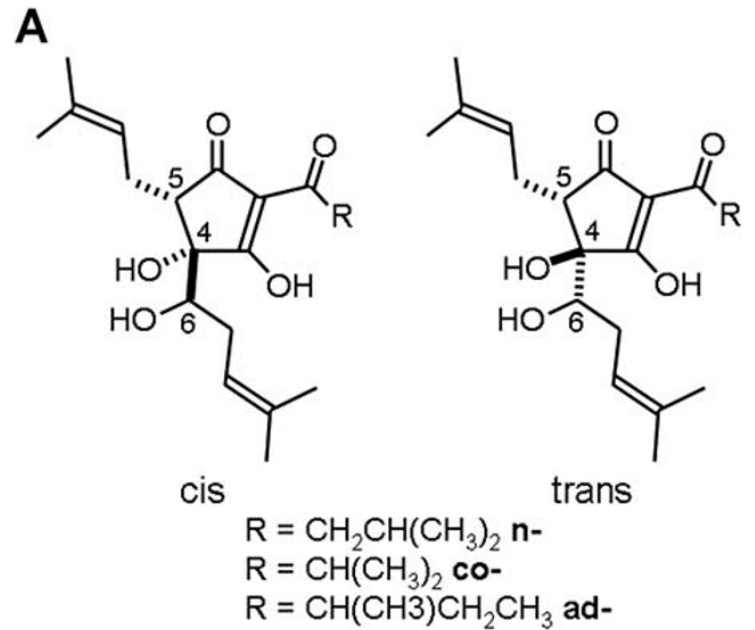

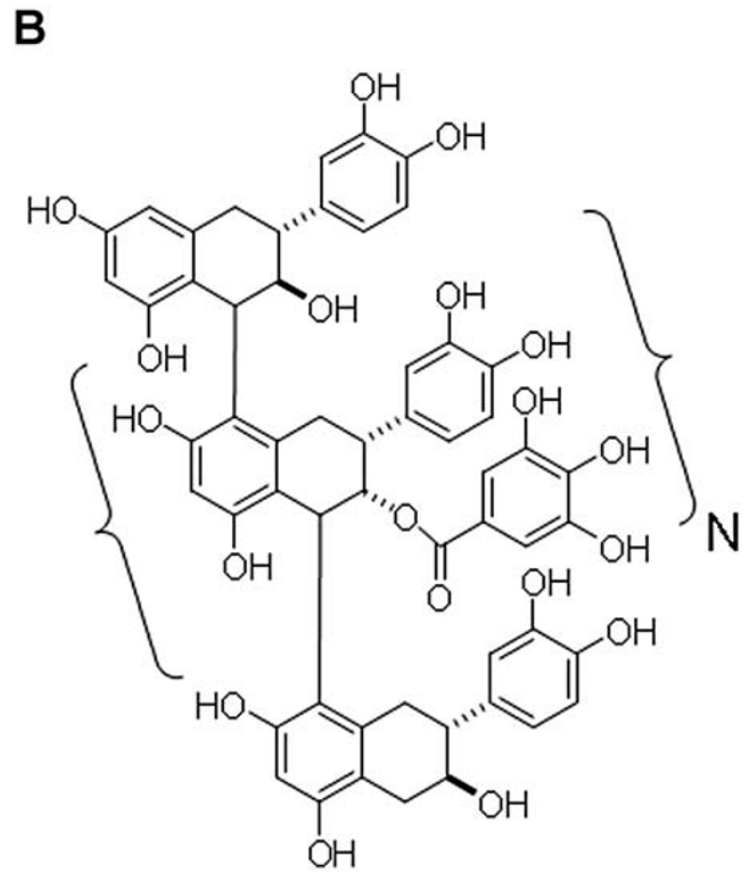

\section{Figure 2}

Structural formula of (A) rho iso-alpha acids from Humulus lupulus $L$. and (B) proanthocyanidins from Acacia nilotica bark extract ( $N=$ 4-1 0 for oligomeric, and $>\mathbf{~} \mathbf{0}$ for polymeric fractions). rho iso-alpha acids formulation contains approximately $25 \%$ inorganic salts, eg., $\mathrm{Mg}^{+2}, \mathrm{~K}^{+}$, and $\mathrm{SO}_{4}{ }^{-2}, 5 \%$ low-molecular resin and $68 \%$ total rho iso-alpha acids, as a mixture of related analogs and diastereomers with a ratio of cis to trans of $3: I$ and a ratio of coto $\mathrm{n}$ - of I:2.2. The aqueous/methanol acacia extract consists of approximately $16 \%$ small molecule catechins and gallates, $28 \%$ oligomeric proanthocyanidins with a degree of polymerization of 4-8 and $56 \%$ polymeric proanthocyanidins with a degree of polymerization of 58 . 
program over the preceding 6 weeks. Of the 26 subjects randomized to the PED arm, 25 completed 8 weeks and 23 completed the trial; of the 23 subjects assigned to the MED arm, 19 completed 8 weeks and 18 completed the trial. Among those who did not complete the trial, all but 1 withdrew due to personal issues (e.g. traveling distance); one subject reported intolerance to the powdered beverage. Approximately two-thirds of the subjects (66\%) were women. The average age of the participants was 53 years, and $82 \%$ of the subjects were obese (BMI $\geq 30)$. Overall, both arms were well matched with respect to the initial variables. However, the mean baseline HbA1c was higher in MED than PED subjects $(6.04 \%$ vs. $5.70 \%, P=0.02)$. The complete blood count and complete metabolic profile variables for all subjects remained stable within the reference ranges (data not shown). One subject in each arm was accepted outside of study criteria meeting 2 rather than at least 3 components of MetS. Both were women; one in the MED arm with borderline waist circumference of 34 inches; the other in the PED arm with borderline TG $1.63 \mathrm{mmol} / \mathrm{L}$. In addition, at baseline, two other subjects in the PED arm no longer met MetS criteria.

\section{Caloric and macronutrient intake, study compliance, and food craving}

No differences between the groups were noted at baseline in dietary caloric or macronutrient intake (Table 2), and taking into account supplementation, the glycemic load did not differ between arms at 8 weeks and 12 weeks. The total caloric intake and daily fat consumption, especially the saturated fatty acid, declined in both arms but the difference between arms at 8 weeks and 12 weeks was not significant. Monounsaturated fatty acid intake decreased in both arms compared to their baseline, but the percent energy from monounsaturated fatty acids remained unchanged throughout the study $(10.0 \%$ at baseline and $10.2 \%$ at 12 weeks for PED; $10.8 \%$ at baseline and $11.2 \%$ at 12 weeks for MED). The carbohydrate intake decreased in both arms over time. The intake of soluble fiber increased 5-fold in the PED arm at 8 weeks and 12 weeks but only 1.5 -fold in the MED arm. Daily consumption of protein by PED subjects increased over time ( $16 \%$ increase by 12 weeks) whereas it decreased in the MED subjects ( $13 \%$ decrease by 12 weeks). Alcohol consumption declined in both arm but the difference between arms at 8 weeks and 12 weeks was not significant.

With respect to overall exercise compliance, the two arms were well matched at baseline, and compliance did not change over the course of the trial according to evaluation of the 7-day exercise diaries. Dietary compliance, as evaluated by glycemic load, did not differ at either 8 weeks or 12 weeks between groups, and glycemic loads of both arms were $<65$. Compliance for the supplementation in the PED arm was high, with 93\% for the powdered bever- age and 95\% for the phytochemical tablet. Craving for fast foods was greater at baseline in the MED $(P=0.03)$ than the PED arm. Cravings decreased significantly from baseline for sweets, fast foods, fats, and carbohydrates by 2 weeks and remained significantly reduced in both arms throughout the 12 weeks of study. There were no statistical differences between the arms from 2 weeks through 12 weeks. Also, hunger/satiety did not differ at baseline between the arms. Hunger between the three major meals (breakfast, lunch, and dinner), and general hunger throughout the day decreased from baseline to 8 and 12 weeks in subjects on both arms. However, hunger between the end of the evening meal and retiring decreased significantly only in the PED arm at both 8 and 12 weeks $(-1.88 \pm 0.39, P<0.01$, and $-1.63 \pm 0.47, P<$ 0.05 , respectively), but not in the MED arm $(-0.49 \pm 0.56$ and $-0.82 \pm 0.57$, respectively). No differences between the arms were noted in quality-of-life questionnaire form Medical Outcome Study Short Form 36 (data not shown).

\section{Weight loss, waist circumference, and BP}

Although this was not designed to be a weight-loss study, subjects in both arms who completed the 12-week study lost nearly identical amounts of weight (PED arm, $-5.9 \pm$ $0.7 \mathrm{~kg}$; MED arm, $-5.7 \pm 1.0 \mathrm{~kg}$ ). Similarly, in both groups, waist circumference was reduced significantly $(P<0.01)$ at 8 and 12 weeks. With regard to BP, subjects in the PED arm experienced reductions in both systolic and diastolic $\mathrm{BP}$ at the end of the trial; from $129.7 \pm 3.5 \mathrm{~mm}$ Hg at base-

Table I: Baseline characteristics of study participants I

\begin{tabular}{|c|c|c|c|}
\hline & PED arm & MED arm & $P$ value \\
\hline$n^{2}$ & 25 & 19 & \\
\hline \multicolumn{4}{|l|}{ Sex } \\
\hline Men & 9 & 6 & \\
\hline Women & 16 & 13 & \\
\hline Age, year & $53.3 \pm 2.4$ & $51.7 \pm 2.1$ & 0.65 \\
\hline Wt, kg & $95.3 \pm 3.8$ & $99.6 \pm 3.6$ & 0.42 \\
\hline Waist, $\mathrm{cm}$ & $106.9 \pm 2.0$ & $111.6 \pm 3.0$ & 0.18 \\
\hline $\mathrm{BMI}, \mathrm{kg} / \mathrm{m}^{2}$ & $33.2 \pm 0.8$ & $35.2 \pm 0.9$ & 0.09 \\
\hline \multicolumn{4}{|l|}{$\mathrm{BP}, \mathrm{mmHg}$} \\
\hline Systolic & $129.7 \pm 3.5$ & $132.8 \pm 3.6$ & 0.54 \\
\hline Diastolic & $87.0 \pm 2.3$ & $85.2 \pm 2.0$ & 0.57 \\
\hline Fasting glucose, $\mathrm{mmol} / \mathrm{L}$ & $5.49 \pm 0.10$ & $5.63 \pm 0.11$ & 0.40 \\
\hline Fasting insulin, pmol/L & $82.65 \pm 8.33$ & $110.43 \pm 13.13$ & 0.07 \\
\hline $\mathrm{HbAIc, \%}$ & $5.7 \pm 0.1$ & $6.0 \pm 0.1$ & 0.02 \\
\hline Cholesterol, $\mathrm{mmol} / \mathrm{L}$ & $6.57 \pm 0.15$ & $6.67 \pm 0.20$ & 0.71 \\
\hline $\mathrm{LDL}, \mathrm{mmol} / \mathrm{L}$ & $4.39 \pm 0.17^{3}$ & $4.64 \pm 0.20^{4}$ & 0.34 \\
\hline $\mathrm{TG}, \mathrm{mmol} / \mathrm{L}$ & $2.78 \pm 0.22$ & $2.37 \pm 0.23$ & 0.21 \\
\hline HDL, mmol/L & $0.98 \pm 0.05$ & $1.02 \pm 0.05$ & 0.65 \\
\hline TG/HDL & $3.07 \pm 1.7$ & $2.50 \pm 1.4$ & 0.23 \\
\hline
\end{tabular}

IValues for continuous variables are means \pm SE

2Subjects completing at least 8 weeks of study

${ }^{3}$ Data from 23 subjects

${ }^{4}$ Data from 17 subjects 
line to $123.4 \pm 2.7 \mathrm{~mm} \mathrm{Hg}$ at 12 weeks for systolic BP $(P$ $=0.025)$; and from $87.0 \pm 2.3 \mathrm{~mm} \mathrm{Hg}$ at baseline to 82.0 $\pm 2.0 \mathrm{~mm} \mathrm{Hg}$ at 12 weeks for diastolic BP $(P=0.005)$. Subjects in the MED arm, on the other hand, displayed a decline only in systolic BP $(132.8 \pm 3.6 \mathrm{~mm}$ Hg at baseline to $128.1 \pm 1.8 \mathrm{~mm} \mathrm{Hg}$ at 12 weeks, $P=0.03$ ); their diastolic BP remained unchanged throughout the study (85.2 \pm $2.0 \mathrm{~mm} \mathrm{Hg}$ at baseline to $84.4 \pm 1.6 \mathrm{~mm} \mathrm{Hg}$ ).

\section{Serum lipids and apolipoproteins}

Effects of intervention diets on cardiometabolic risk variables are summarized in Table 3 and individual responses are illustrated in Fig. 3. Subjects in both arms experienced reductions in total cholesterol, LDL, non-HDL cholesterol, and cholesterol/HDL at 8 weeks and 12 weeks of the trial. The decrease in total cholesterol and non-HDL cholesterol from baseline to 12 weeks was greater in the PED than in the MED arm $(P=0.03$ and 0.02 , respectively): the average percent reduction in total cholesterol was $14.5 \%$ in the PED arm but only $6.3 \%$ in the MED arm and in non-HDL cholesterol was $18.2 \%$ in the PED arm but only $8.0 \%$ in the MED arm. The decrease in cholesterol/HDL was greater in the PED than in the MED arm $(P=0.01)$. With regard to serum TG and TG/HDL, a recognized marker of MetS, subjects in both arms experienced reductions at 8 weeks. However, only subjects in the PED arm continued to exhibit decreases in serum TG and TG/HDL at 12 weeks; the difference between the 2 arms was significant at 12 weeks ( $P=0.03$ and 0.02 , respectively). There was an average $42.7 \%$ reduction in TG/HDL in the PED arm and only a $17.6 \%$ decrease in the MED arm. Serum HDL increased from baseline to 12 weeks only in subjects on the PED arm $(P<0.05)$, and remained unchanged in the MED arm. Compared to baseline, the total LDL particle number decreased in the PED arm at 8 and 12 weeks, and in the MED arm only at 12 weeks. VLDL particle number decreased at both 8 and 12 weeks only in the PED arm; large HDL particle number increased in both arms at 8 and 12 weeks (data not shown). With respect to lipoprotein variables, both PED and MED arms showed reduction of apo B concentration and apo B/apo A-I at 8 weeks compared to baseline; however, only the PED arm exhibited continued reduction in both variables from 8 weeks to 12 weeks. Additional adjustment for calorie and carbohy-

Table 2: Caloric and nutrient intake at baseline, 8 weeks and 12 weeks

\begin{tabular}{|c|c|c|c|c|}
\hline Nutrient & Visit & PED arm ${ }^{\prime}$ & MED arm $^{2}$ & $P$ value (between arms) \\
\hline & \multicolumn{4}{|c|}{ mean $\pm S E$} \\
\hline \multirow{3}{*}{ Total energy $(k J / d)$} & Baseline & $9654 \pm 571$ & $11575 \pm 1619$ & 0.22 \\
\hline & 8 weeks & $6699 \pm 370$ & $6171 \pm 479$ & 0.38 \\
\hline & 12 weeks & $6442 \pm 285$ & $5835 \pm 472$ & 0.25 \\
\hline \multirow[t]{3}{*}{ Carbohydrates (g/d) } & Baseline & $261.7 \pm 19.0$ & $337.9 \pm 45.8$ & 0.10 \\
\hline & 8 weeks & $188.9 \pm 10.9$ & $150.9 \pm 13.8$ & 0.03 \\
\hline & 12 weeks & $169.6 \pm 9.3$ & $151.4 \pm 13.6$ & 0.22 \\
\hline \multirow[t]{3}{*}{ Insoluble fiber ( $g / d)$} & Baseline & $6.0 \pm 0.7$ & $4.3 \pm 0.6$ & 0.09 \\
\hline & 8 weeks & $10.4 \pm 1.3$ & $8.1 \pm 1.0$ & 0.17 \\
\hline & 12 weeks & $9.4 \pm 1.0$ & $8.3 \pm 1.4$ & 0.51 \\
\hline \multirow[t]{3}{*}{ Soluble fiber $(g / d)$} & Baseline & $2.3 \pm 0.3$ & $2.1 \pm 0.3$ & 0.58 \\
\hline & 8 weeks & $11.8 \pm 0.5$ & $3.1 \pm 0.4$ & $<0.01$ \\
\hline & 12 weeks & $11.5 \pm 0.3$ & $3.3 \pm 0.5$ & $<0.01$ \\
\hline \multirow[t]{3}{*}{ Protein $(g / d)$} & Baseline & $100.2 \pm 7.0$ & $97.7 \pm 13.0$ & 0.86 \\
\hline & 8 weeks & || $2.5 \pm 6 . \mid$ & $90.7 \pm 7.2$ & 0.03 \\
\hline & 12 weeks & $116.1 \pm 7.6$ & $85.3 \pm 7.9$ & 0.01 \\
\hline \multirow[t]{3}{*}{ Fat $(g / d)$} & Baseline & $96.2 \pm 7.4$ & $113.5 \pm 17.1$ & 0.32 \\
\hline & 8 weeks & $47.6 \pm 3.7$ & $59.5 \pm 5.18$ & 0.06 \\
\hline & 12 weeks & $46.8 \pm 4.7$ & $52.7 \pm 5.19$ & 0.40 \\
\hline \multirow[t]{3}{*}{ Saturated fatty acid $(g / d)$} & Baseline & $30.5 \pm 2.9$ & $35.0 \pm 4.5$ & 0.39 \\
\hline & 8 weeks & $10.5 \pm 0.9$ & $14.0 \pm 1.7$ & 0.05 \\
\hline & 12 weeks & $10.1 \pm 1.1$ & $12.8 \pm 1.3$ & 0.11 \\
\hline \multirow[t]{3}{*}{ Monounsaturated fatty acid $(g / d)$} & Baseline & $25.6 \pm 3.1$ & $33.1 \pm 5.5$ & 0.21 \\
\hline & 8 weeks & $14.8 \pm 1.5$ & $19.7 \pm 1.7$ & 0.04 \\
\hline & 12 weeks & $17.4 \pm 2.2$ & $17.4 \pm 2.3$ & 0.98 \\
\hline \multirow[t]{3}{*}{ Cholesterol (mmol/d) } & Baseline & $9.48 \pm 0.96$ & $9.22 \pm 1.10$ & 0.86 \\
\hline & 8 weeks & $6.31 \pm 0.69$ & $10.01 \pm 1.38$ & 0.01 \\
\hline & 12 weeks & $6.79 \pm 0.94$ & $8.33 \pm 1.03$ & 0.34 \\
\hline \multirow[t]{3}{*}{ Alcohol $(g / d)$} & Baseline & $4.9 \pm 1.4$ & $3.3 \pm 2.3$ & 0.56 \\
\hline & 8 weeks & $1.2 \pm 0.8$ & $3.1 \pm 1.2$ & 0.19 \\
\hline & 12 weeks & $1.6 \pm 0.9$ & $2.1 \pm 1.3$ & 0.75 \\
\hline
\end{tabular}

IPED arm: Baseline \& 8 weeks, $n=25$; 12 weeks, $n=23$. ${ }^{2}$ MED arm: Baseline \& 8 weeks, $n=19 ; 12$ weeks, $n=18$. 
drate intake, and body weight change for these variables did not change the findings (adjusted P values in Table 3 ).

\section{Glucose, insulin, HbAlc, and HOMA score}

Subjects in both arms exhibited decrease in fasting insulin concentrations and HbA1c at 8 and 12 weeks comparing to baseline (Table 3 ). With respect to fasting glucose, only subjects in the MED arm displayed reduction from baseline at 12 weeks. A reduction in HOMA score was observed in PED arm at both 8 weeks and 12 weeks, but in MED arm only at 8 weeks. No differences between arms were observed with respect to fasting insulin, fasting glucose, HOMA score, and HbA1c at both 8 and 12 weeks. Additional adjustment for calorie and carbohydrate intake, and body weight change for these variables did not change the findings (adjusted $\mathrm{P}$ values in Table 3 ).

\section{Metabolic syndrome variables and Framingham 10-year CVD risk score}

At baseline, 23 subjects in the PED arm and 22 subjects in the MED arm met at least 3 of 5 criteria for MetS. The mean number of MetS criteria for the PED arm including only those subjects with MetS at baseline and only those completing 12 weeks was $3.81 \pm 0.18(\mathrm{n}=21)$, and 4.17 $\pm 0.19(\mathrm{n}=18)$ for the MED arm. After 12 weeks on the trial, the number of MetS variables reduced to $2.95 \pm 0.26$ in the PED $\operatorname{arm}(P=0.01)$, and to $3.56 \pm 0.28$ in the MED $\operatorname{arm}(P=0.07)$. At the end of 12 weeks, 9 of the 21 subjects (43\%) in PED arm no longer met criteria for MetS compared with only 4 of the 18 subjects $(22 \%)$ in the MED arm. The calculated Framingham 10-year CVD risk score in subjects finishing all visits of the trial fell from $15.3 \pm$ $2.5 \%$ at baseline to $9.6 \pm 1.4 \%$ at 12 weeks in the PED arm $(P<0.001)$, and from $16.0 \pm 3.0 \%$ at baseline to $13.1 \pm$ $2.7 \%$ at 12 weeks for the MED arm $(P=0.011)$.

\section{Discussion}

Due to the complex mechanistic underpinnings of MetS, strategies for reducing its incidence and consequences need to be similarly comprehensive and multi-factorial. Targeting multiple, chronically dysregulated signaling pathways at play in insulin resistance is likely to yield the greatest benefit [45] in the treatment of MetS. To our knowledge, this is the first intervention study to successfully demonstrate the concept of modifying cardiometabolic risk factors by combining a modified Mediterranean-style, low glycemic load dietary pattern, and regular exercise, with diverse phytochemicals targeting multiple signaling abnormalities of MetS. A greater than 2-fold improvement in total cholesterol, non-HDL cholesterol, TG, cholesterol/HDL, and TG/HDL were observed with the addition of soy protein, phytosterols, hops RIAA, and acacia PAC to a modified Mediterraneanstyle low glycemic load diet and exercise program. Increase in HDL and decrease in LDL and VLDL particle numbers were seen only in the PED arm. Also, diastolic BP fell only in the PED arm. Furthermore, by 12 weeks, almost double the number of subjects experienced a net resolution of MetS in the PED group compared with MED group, and the PED group experienced almost twice the reduction in the Framingham 10-year CVD risk score as the MED group. Overall, CVD risk was reduced to a greater degree in the subjects supplemented with phytochemicals relative to the subjects on MED alone.

Previously [37], we compared a calorically-restricted version of the diet used in this study supplemented with soy protein and phytosterols to the frequently-studied AHA Step I low-fat diet in postmenopausal hypercholesterolemic women. We demonstrated that this targeted phytochemical, supplemented diet produced greater benefits than the AHA diet alone. The protocol for the current trial differed from that of our previous study in 2 key aspects: (i) subjects in both study arms were instructed to consume their diet until satisfied, and (ii) 2 additional supplemental phytochemicals were provided to target the underlying inflammatory mechanisms of MetS. The modified Mediterranean-style, low glycemic load diet by itself is an effective approach to weight loss and CVD risk reduction [46]. Our findings suggest that the addition of the soy protein, phytosterols, in combination with targeted phytochemicals was responsible for the more favorable CVD risk profile outcome in the PED group. This observation could not be attributed to greater weight loss in the PED group, since the extent of weight loss was similar on both arms. A recent review by Volek and Feinman reported that dietary carbohydrate may affect various cardiometabolic factors [10]. In our analysis, we adjusted for calorie and carbohydrate intake, and body weight change, and found that the observed differences between arms remained unaffected (Table 3). Likewise, the glycemic loads of the diets and the levels of exercise did not differ between arms. Although provision of the powdered beverage may have simplified meal planning, and in turn, enhanced dietary compliance and convenience, an effect similar to that reported by Noakes et al. [47], again weight loss did not differ. Finally, although only subjects in the PED arm experienced a decrease in hunger levels in the period between the evening meal and bedtime, which might have reduced excessive, nighttime snacking, differences in intake should have been reflected in differential body weight loss and recorded caloric intake, neither of which occurred.

RIAA is a modified hop extract that has been used in beer for flavoring, foam stability and bittering for decades, and is prized for its chemical stability. RIAA is derived from hop cones in a process that first involves extraction of whole hops with supercritical $\mathrm{CO}_{2}$, yielding an extract containing a mixture of alpha acids, beta acids and hop 
Table 3: Effect of intervention diets on cardiovascular risk variables at baseline, 8 weeks and I 2 weeks of intervention

\begin{tabular}{|c|c|c|c|c|c|c|c|}
\hline \multirow[t]{2}{*}{ Variable } & \multirow[t]{2}{*}{ Visit } & \multicolumn{2}{|c|}{ PED arm } & \multicolumn{2}{|c|}{ MED arm } & \multirow{2}{*}{$\begin{array}{c}P_{\text {value }}^{2} \\
\text { (Difference } \\
\text { between arm) }\end{array}$} & \multirow{2}{*}{$\begin{array}{l}\text { Adjusted } P \\
\text { value }^{3}\end{array}$} \\
\hline & & Value (mean $\pm S E$ ) & $\begin{array}{l}\text { Mean \% change } \\
\text { from baseline }\end{array}$ & Value (mean $\pm S E$ ) & $\begin{array}{l}\text { Mean \% change } \\
\text { from baseline }\end{array}$ & & \\
\hline \multirow[t]{3}{*}{ Cholesterol (mmol/L) } & Baseline & $6.57 \pm 0.15$ & & $6.67 \pm 0.20$ & & & \\
\hline & 8 weeks & $5.67 \pm 0.22 * *$ & $-13.8 \%$ & $6.09 \pm 0.25 * *$ & $-8.7 \%$ & 0.13 & 0.04 \\
\hline & 12 weeks & $5.59 \pm 0.14^{* *}$ & $-14.5 \%$ & $6.27 \pm 0.22 *$ & $-6.3 \%$ & 0.03 & 0.04 \\
\hline \multirow[t]{3}{*}{ TG $(m m o l / L)$} & Baseline & $2.78 \pm 0.22$ & & $2.37 \pm 0.23$ & & & \\
\hline & 8 weeks & $2.02 \pm 0.25^{* *}$ & $-27.2 \%$ & $1.84 \pm 0.17^{* *}$ & $-22.3 \%$ & 0.27 & 0.05 \\
\hline & 12 weeks & $1.86 \pm 0.12^{* *}$ & $-35.2 \%$ & $2.09 \pm 0.19$ & $-14.3 \%$ & 0.03 & 0.01 \\
\hline \multirow[t]{3}{*}{$\mathrm{HDL}(\mathrm{mmol} / \mathrm{L})$} & Baseline & $0.98 \pm 0.05$ & & $1.02 \pm 0.05$ & & & \\
\hline & 8 weeks & $0.99 \pm 0.05$ & $0.7 \%$ & $1.00 \pm 0.04$ & $-1.6 \%$ & 0.34 & 0.45 \\
\hline & 12 weeks & $1.05 \pm 0.05^{*}$ & $7.0 \%$ & $1.04 \pm 0.05$ & $2.7 \%$ & 0.18 & 0.21 \\
\hline \multirow[t]{3}{*}{$\operatorname{LDL}(m m o l / L)$} & Baseline & $4.39 \pm 0.17$ & & $4.64 \pm 0.20$ & & & \\
\hline & 8 weeks & $3.78 \pm 0.19 * *$ & $-16.8 \%$ & $4.24 \pm 0.20 * *$ & $-9.8 \%$ & 0.11 & 0.19 \\
\hline & 12 weeks & $3.69 \pm 0.12^{* *}$ & $-17.3 \%$ & $4.28 \pm 0.17^{*}$ & $-8.4 \%$ & 0.11 & 0.18 \\
\hline \multirow{3}{*}{$\begin{array}{l}\text { Non-HDL } \\
\text { cholesterol (mmol/L) }\end{array}$} & Baseline & $5.59 \pm 0.14$ & & $5.65 \pm 0.19$ & & & \\
\hline & 8 weeks & $4.67 \pm 0.20 * *$ & $-16.4 \%$ & $5.09 \pm 0.25^{* *}$ & $10.0 \%$ & 0.19 & 0.03 \\
\hline & 12 weeks & $4.54 \pm 0.14^{* *}$ & $-18.2 \%$ & $5.23 \pm 0.22 *$ & $-8.0 \%$ & 0.02 & 0.03 \\
\hline \multirow{3}{*}{$\begin{array}{l}\text { LDL particle number } \\
\text { (nmol/L) }\end{array}$} & Baseline & $1634 \pm 57$ & & $1733 \pm 84$ & & & \\
\hline & 8 weeks & $1453 \pm 63^{*}$ & $-11.9 \%$ & $1618 \pm 108$ & $-6.6 \%$ & 0.24 & 0.19 \\
\hline & 12 weeks & $1455 \pm 63^{*}$ & $-11.9 \%$ & $1629 \pm 109 *$ & $-7.0 \%$ & 0.26 & 0.31 \\
\hline \multirow[t]{3}{*}{ Chol/HDL } & Baseline & $6.9 \pm 0.3$ & & $6.8 \pm 0.3$ & & & \\
\hline & 8 weeks & $5.9 \pm 0.3^{* *}$ & $-14.3 \%$ & $6.2 \pm 0.3 * *$ & $-9.0 \%$ & 0.13 & 0.09 \\
\hline & 12 weeks & $5.6 \pm 0.3 * *$ & $-19.5 \%$ & $6.3 \pm 0.4^{* *}$ & $-8.9 \%$ & 0.01 & 0.02 \\
\hline \multirow[t]{3}{*}{ TG/HDL } & Baseline & $3.1 \pm 1.7$ & & $2.5 \pm 1.4$ & & & \\
\hline & 8 weeks & $2.1 \pm 1.3^{* *}$ & $-30.6 \%$ & $1.9 \pm 0.9 * *$ & $-23.2 \%$ & 0.20 & 0.07 \\
\hline & 12 weeks & $1.9 \pm 0.7^{* *}$ & $-42.7 \%$ & $2.1 \pm 1.1$ & $-17.6 \%$ & 0.02 & 0.01 \\
\hline \multirow{3}{*}{ apo A-I $(g / L)$} & Baseline & $1.94 \pm 0.06$ & & $1.96 \pm 0.07$ & & & \\
\hline & 8 weeks & $1.89 \pm 0.05$ & $-2.5 \%$ & $1.88 \pm 0.06$ & $-3.9 \%$ & 0.32 & 0.30 \\
\hline & 12 weeks & $1.90 \pm 0.06$ & $-2.1 \%$ & $1.87 \pm 0.06$ & $-4.3 \%$ & 0.24 & 0.16 \\
\hline \multirow[t]{3}{*}{ apo B (g/L) } & Baseline & $1.48 \pm 0.05$ & & $1.50 \pm 0.06$ & & & \\
\hline & 8 weeks & $1.30 \pm 0.05^{* *}$ & $-12.1 \%$ & $1.36 \pm 0.06 * *$ & $-9.9 \%$ & 0.32 & 0.21 \\
\hline & 12 weeks & $1.21 \pm 0.04^{* *}$ & $-17.5 \%$ & $1.36 \pm 0.06 * *$ & $-9.9 \%$ & 0.09 & 0.14 \\
\hline \multirow[t]{3}{*}{ apoB/apoA-I } & Baseline & $0.78 \pm 0.03$ & & $0.78 \pm 0.04$ & & & \\
\hline & 8 weeks & $0.70 \pm 0.03 *$ & $-10.3 \%$ & $0.73 \pm 0.04 *$ & $-6.4 \%$ & 0.26 & 0.13 \\
\hline & 12 weeks & $0.66 \pm 0.03 * *$ & $-15.4 \%$ & $0.75 \pm 0.05^{*}$ & $-6.3 \%$ & 0.07 & 0.08 \\
\hline \multirow{3}{*}{$\begin{array}{l}\text { Fasting Glucose } \\
(\mathrm{mmol} / \mathrm{L})\end{array}$} & Baseline & $5.49 \pm 0.10$ & & $5.63 \pm 0.11$ & & & \\
\hline & 8 weeks & $5.31 \pm 0.11$ & $-3.3 \%$ & $5.46 \pm 0.10$ & $-2.9 \%$ & 0.45 & 0.42 \\
\hline & 12 weeks & $5.39 \pm 0.10$ & $-2.2 \%$ & $5.41 \pm 0.12 *$ & $-4.8 \%$ & 0.85 & 0.92 \\
\hline \multirow{3}{*}{$\begin{array}{l}\text { Fasting Insulin (pmoll } \\
L \text { ) }\end{array}$} & Baseline & $82.65 \pm 8.33$ & & $110.43 \pm 13.13$ & & & \\
\hline & 8 weeks & $53.48 \pm 4.58^{* *}$ & $-35.2 \%$ & $75.70 \pm 10.42 *$ & $-31.0 \%$ & 0.66 & 0.82 \\
\hline & 12 weeks & $60.42 \pm 5.69 * *$ & $-26.8 \%$ & $88.90 \pm 11.74 *$ & $-22.3 \%$ & 0.59 & 0.74 \\
\hline \multirow[t]{3}{*}{ HOMA' } & Baseline & $3.0 \pm 0.4$ & & $4.1 \pm 0.6$ & & & \\
\hline & 8 weeks & $1.8 \pm 0.2^{* *}$ & $-38.9 \%$ & $2.7 \pm 0.4^{*}$ & $-32.6 \%$ & 0.63 & 0.81 \\
\hline & 12 weeks & $2.0 \pm 0.2^{*}$ & $-29.7 \%$ & $3.0 \pm 0.5$ & $-24.9 \%$ & 0.61 & 0.76 \\
\hline \multirow[t]{3}{*}{$\mathrm{HbAlc} \%$} & Baseline & $5.7 \pm 0.1$ & & $6.0 \pm 0.1$ & & & \\
\hline & 8 weeks & $5.6 \pm 0.1^{*}$ & $-1.9 \%$ & $5.9 \pm 0.1 * *$ & $-2.7 \%$ & 0.77 & 0.72 \\
\hline & 12 weeks & $5.6 \pm 0.1^{* *}$ & $-2.6 \%$ & $5.8 \pm 0.1^{* *}$ & $-3.8 \%$ & 0.82 & 0.87 \\
\hline
\end{tabular}

*Different from baseline, $P<0.05$

$* *$ Different from baseline, $P<0.01$

IHOMA score calculated as follows: [(insulin (pmol/L)*glucose (mmol/L))//35].

${ }^{2}$ Comparing the values between arms using I-sided unpaired $\mathrm{t}$-test

${ }^{3}$ Adjusted for body weight, caloric intake, and carbohydrate intake 
oils $[48,49]$. The alpha acids are differentially isolated, isomerized, and reduced to form RIAA. The Acacia nilotica tree grows naturally in many arid climates in Australia, Africa, and India and the young trees are a food source for many animals including cattle [50-52]. The young leaves have been fried and consumed like other leafy vegetables. The bark is ingested traditionally as a hot beverage and in a more concentrated form as a folk medicine for various ailments including colds, diarrhea, tuberculosis and leprosy [53]. The rationale for inclusion of the RIAA/PAC tablet was based on results of in vitro screening studies employing insulin resistant 3T3-L1 adipocytes, $d b / d b$ mouse diabetes studies, and a pilot clinical trial (unpublished results); all consistently showing improvement in insulin sensitivity. Briefly, the RIAA/PAC combination displayed lipogenic and anti-inflammatory activity in murine 3T3-L1 adipocytes stimulated with TNF $\alpha$. Both agents inhibited TNF $\alpha$-stimulated IL- 6 secretion and improved adiponectin secretion. Individually and in various combinations these compounds also demonstrated favorable modulation of the activity of proteins and kinases implicated in insulin signaling such as PI3K, GSK3, AKT, PKC and c-Jun N-terminal kinase (manuscript in preparation). Other groups have reported that feeding of isohumulone, which is structurally similar to RIAA, to C57BL/6N mice reduced plasma TG and free fatty acid levels [54]. Additional animal and clinical studies with isohumulone have revealed that: (i) diabetic KK-Ay mice had reduced plasma glucose, TG, and free fatty acid levels, 65.3, 62.6, and $73.1 \%$, respectively; (ii) C57BL/6N mice fed a high fat diet showed improved glucose tolerance and reduced insulin resistance; and (iii) a double-blind, placebo-controlled pilot study on diabetic subjects suggested that isohumulones decreased blood glucose and HbA1c levels by 10.1 and $6.4 \%$, respectively, after 8 weeks [55]. We chose RIAA over IAA due to RIAA's greater chemical stability [48], potent in vitro anti-inflammatory activity in 3T3-L1 adipocytes. In our pilot clinical trial a combination of RIAA and PAC in tablet form significantly improved LDL, TG and TG/HDL in subjects with MetS.

The results of the present study, in agreement with similar studies reported by others [25-28], confirm the benefits of lifestyle intervention consisting of a phytochemical rich, low glycemic load diet and a moderate aerobic exercise regimen in subjects with MetS. For example, Jenkins et al. [56] found reductions in lipid variables with an ad libitum low glycemic load diet ("portfolio diet") in subjects with high TG at baseline. The average reductions reported by Jenkins et al. in total cholesterol, LDL and TG over one month were almost identical to those noted in the MED arm of the present study over 8 weeks ( $8.8 \%$ vs. $8.7 \%$; $9.1 \%$ vs. $9.8 \%$; and $19.3 \%$ vs. $22.3 \%$, respectively). Also, similar to the results reported by Jenkins et al. [56], no changes in HDL were noted in MED subjects in the present study. Lastly, in both arms of the present trial, we found that subjects' food cravings fell and satiety increased with institution of the low glycemic load diet and energy intake fell despite the lack of instructions to limit caloric intake. Esposito et al. reported that $48 \%$ of subjects with MetS instructed to follow a Mediterraneanstyle (not necessarily low glycemic) diet over 2 years no longer met 3 or more criteria for MetS [57]. In the Diabetes Prevention Program Trial, lifestyle modification led to $38 \%$ resolution of MetS after 3 years [58]. In contrast, only minimal resolution of MetS was seen in the Diabetes Prevention Program Trial after one year with either metformin or lifestyle management [58]. Our study suggests that by complementing a therapeutic lifestyle program with a soy- and phytosterol-based powdered beverage and tablets containing hops RIAA and acacia PAC, subjects can improve to a similar magnitude $(43 \%)$ attained at 2 and 3 years in just 12 weeks.

Most therapeutic treatments for hypercholesterolemia focus on achieving LDL goals recommended by NCEP. However, the NHANES 2003-2004 showed that despite better control of LDL, other lipid risk factors remained suboptimal in many US adults, particularly among those with CVD, diabetes, or MetS [59]. Non-HDL cholesterol, a stronger predictor of CVD and mortality risk than LDL [60-62], has now been added by the NCEP Adult Treatment Panel III as a secondary target of therapy [63]. In addition, because apo $B$ indicates the total number of atherogenic lipoprotein particles and apo A-I, a major lipoprotein in HDL, has a critical role in reverse cholesterol transport, the apo B/apo A-I (as well as apo B concentration) has been proposed as a risk factor for CVD. Increasing evidence from multiple studies has repeatedly shown that the apo $\mathrm{B} /$ apo A-I predicts cardiovascular risk - the lower the ratio, the lower is the risk - and is a better marker than LDL and lipid ratios [64-71]. In the InterHeart study, the apo B/apo A-I was the strongest determinant of MI risk, even higher than smoking; the OR of top vs. lowest decile was 4.73 [72]. The authors state the apo B/apo A-I might be the best marker of the balance of atherogenic and antiatherogenic particles. Subjects in both PED and MED arms showed significant reduction in non-HDL cholesterol and apo B/apo A-I at 8 weeks compared to baseline, but only the PED arm showed continued reduction in the ratio at 12 weeks. These data suggest further cardiovascular benefit from the added phytochemicals.

\section{Conclusion}

The worldwide prevalence and multi-factorial nature of MetS do not reasonably support a pharmacologic approach for treatment or prevention. Fortunately, lifestyle modification including dietary alteration has demonstrated success in correcting metabolic abnormalities 


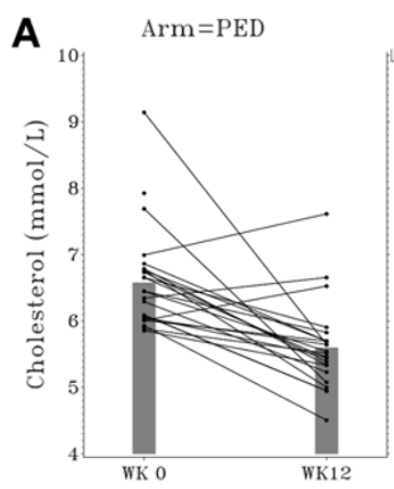

C

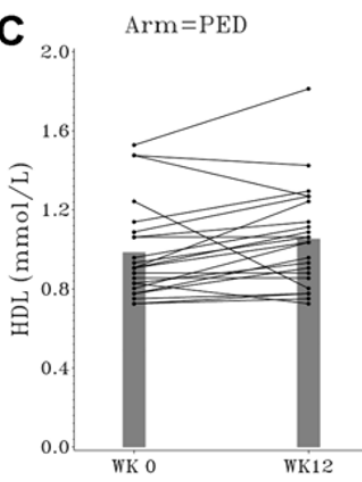

E

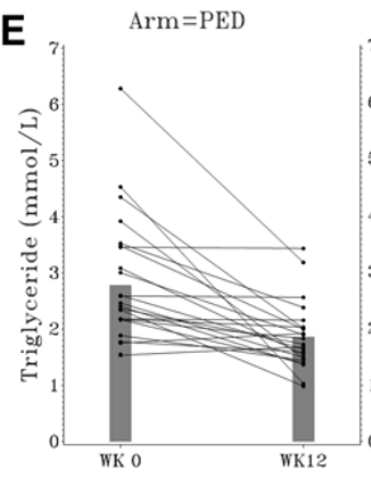

G

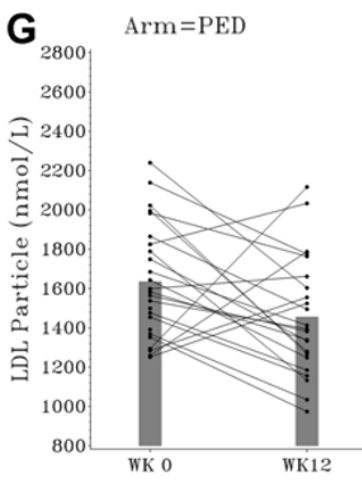

$\mathrm{Arm}=\mathrm{MED}$

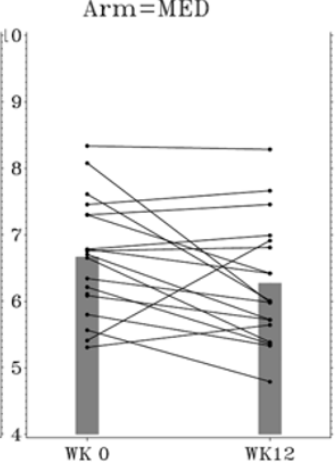

$\operatorname{Arm}=\mathrm{MED}$

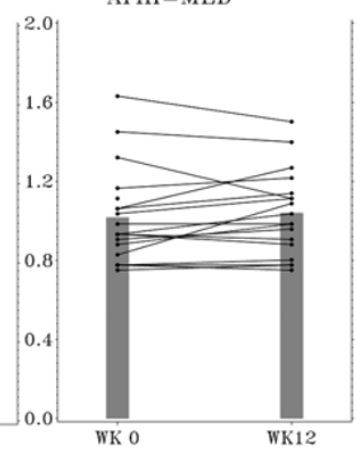

Arm $=$ MED

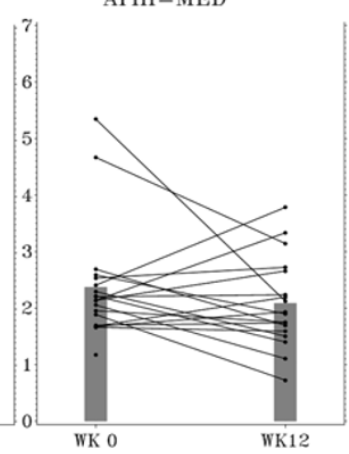

$\operatorname{Arm}=$ MED

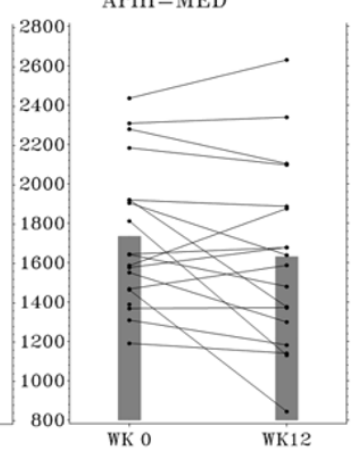

B

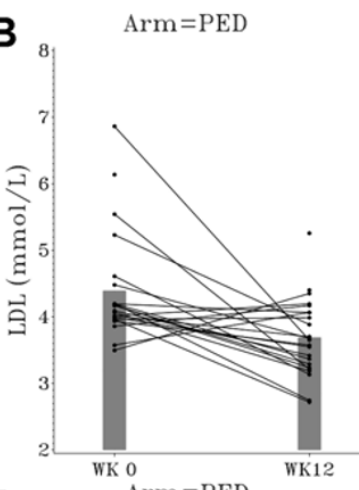

D

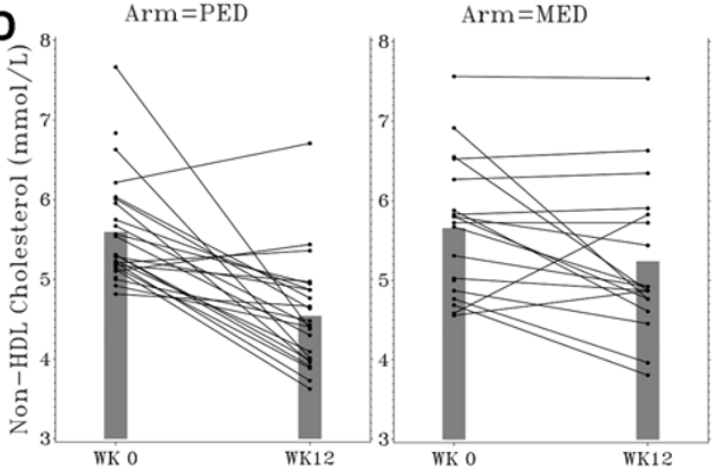

F $\quad$ Arm $=$ PED

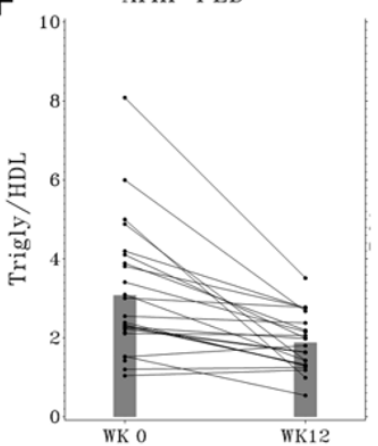

$\operatorname{Arm}=\mathrm{MED}$

H

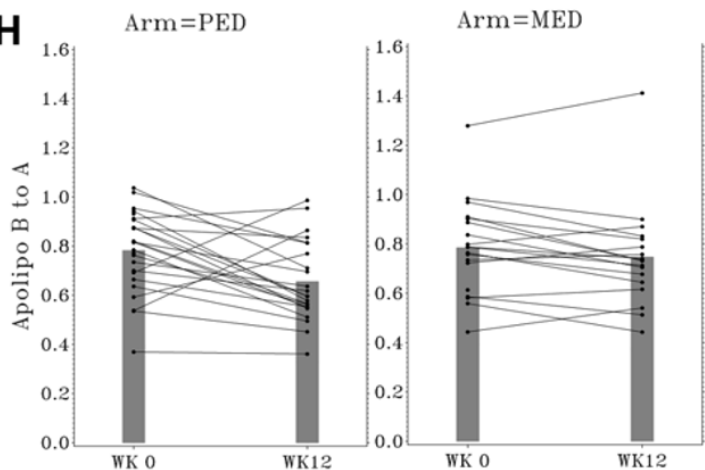

Figure 3

Individual responses in serum lipid parameters (A, total cholesterol; B, LDL; C, HDL; D, non-HDL cholesterol; E, TG; F, TG/HDL; G, LDL particle number; H, apo B/apo A-I) in the intervention (PED) and control (MED) arms at baseline and 12 weeks. Shaded bars indicate mean responses. 
associated with the development of type 2 diabetes and CVD. The present study provides evidence that supplementation of a modified Mediterranean-style, low glycemic load diet with a combination of phytochemicals addressing multiple inflammatory and insulin signaling pathways simultaneously may be a novel, effective means to managing MetS. This comprehensive, supplemented lifestyle program represents a potentially powerful approach to the management of at risk individuals with MetS and hypercholesterolemia.

\section{List of abbreviations}

AHA: American Heart Association; Akt: protein kinase B; apo: apolipoprotein; BMI: body mass index; BP: blood pressure; CVD: cardiovascular disease; GSK-3: glycogen synthase kinase-3; HbA1c: hemoglobin A1c; HOMA: homeostatic model assessment; MED: modified Mediterranean-style low glycemic load diet; MetS: metabolic syndrome; NCEP: National Cholesterol Education Program; PAC: proanthocyanidin; PED: phytochemical - supplemented MED; PI3K: phosphoinositol 3-kinase; PKC: protein kinase C; RIAA: rho iso-alpha acids; TG: triglycerides; TNFo: tumor necrosis factor alpha.

\section{Competing interests}

The study was funded by MetaProteomics, LLC, a subsidiary of Metagenics, Inc that manufactures the commercial medical food, UltraMeal $^{\circledR}$ Plus, for licensed healthcare professionals. The combination nutraceutical referred to in the manuscript is a commercial product (Insinase ${ }^{\mathrm{TM}}$ ) developed by Metagenics, Inc. All authors are employees of MetaProteomics.

\section{Authors' contributions}

All authors participated in the concept and design of the study, and contribute to manuscript preparation. RHL was the principle investigator. RHL, BS, JJL, and DMM conducted the intervention study. DMM and BS provided dietary counseling. RHL, GD, and MLT performed the statistical analysis. All authors read and approved the final manuscript.

\section{Additional material}

\section{Additional file 1}

List of permitted foods and beverages, serving sizes and recipes.

Click here for file

[http://www.biomedcentral.com/content/supplementary/1743-

7075-5-29-S1.pdf]

\section{Additional file 2}

Macronutrient profile of the soy and phytosterol-based powdered beverage.

Click here for file

[http://www.biomedcentral.com/content/supplementary/17437075-5-29-S2.pdf]

\section{Acknowledgements}

We thank Dr. Brian Carroll for analyzing the compositional profile of the hops ingredients and acacia bark extract and providing the chemical structural formula, Dr. David Gray and Alex Hsi for statistical analyses, Dr. JyhLurn Chang for manuscript preparation; and Julie Triggs, Leslie Pilkington, Scott Stockmyer, Mabel Lorenzi-Albe, Lara Wax, Sarah Lerman, Barbara J Delorme, and Darcy Diaz for expert technical assistance.

\section{References}

I. Fito M, Guxens M, Corella D, Saez G, Estruch R, de la Torre R, Frances F, Cabezas C, Lopez-Sabater Mdel C, Marrugat J, Garcia-Arellano A, Aros F, Ruiz-Gutierrez V, Ros E, Salas-Salvado J, Fiol M, Sola $\mathrm{R}$, Covas MI: Effect of a traditional Mediterranean diet on lipoprotein oxidation: a randomized controlled trial. Arch Intern Med 2007, 167: I195-1203.

2. Mitrou PN, Kipnis V, Thiebaut AC, Reedy J, Subar AF, Wirfalt E, Flood A, Mouw T, Hollenbeck AR, Leitzmann MF, Schatzkin A: Mediterranean dietary pattern and prediction of all-cause mortality in a US population: results from the NIH-AARP Diet and Health Study. Arch Intern Med 2007, 167:246I-2468.

3. O'Keefe JH, Bell DS: Postprandial hyperglycemia/hyperlipidemia (postprandial dysmetabolism) is a cardiovascular risk factor. Am J Cardiol 2007, 100:899-904.

4. Eckel RH, Grundy SM, Zimmet PZ: The metabolic syndrome. Lancet 2005, 365: 1415-I428.

5. Moller DE, Kaufman KD: Metabolic syndrome: a clinical and molecular perspective. Annu Rev Med 2005, 56:45-62.

6. Ford ES: Prevalence of the metabolic syndrome defined by the International Diabetes Federation among adults in the U.S. Diabetes Care 2005, 28:2745-2749.

7. Batsis JA, Nieto-Martinez RE, Lopez-Jimenez F: Metabolic syndrome: from global epidemiology to individualized medicine. Clin Pharmacol Ther 2007, 82:509-524.

8. Day C: Metabolic syndrome, or What you will: definitions and epidemiology. Diab Vasc Dis Res 2007, 4:32-38.

9. Forsythe CE, Phinney SD, Fernandez ML, Quann EE, Wood RJ, Bibus DM, Kraemer WJ, Feinman RD, Volek JS: Comparison of low fat and low carbohydrate diets on circulating fatty acid composition and markers of inflammation. Lipids 2008, 43:65-77.

10. Volek JS, Feinman RD: Carbohydrate restriction improves the features of Metabolic Syndrome. Metabolic Syndrome may be defined by the response to carbohydrate restriction. Nutr Metab (Lond) 2005, 2:3I.

II. Volek JS, Fernandez ML, Feinman RD, Phinney SD: Dietary carbohydrate restriction induces a unique metabolic state positively affecting atherogenic dyslipidemia, fatty acid partitioning, and metabolic syndrome. Prog Lipid Res 2008, 47:307-318.

12. Riccardi G, Giacco R, Rivellese AA: Dietary fat, insulin sensitivity and the metabolic syndrome. Clin Nutr 2004, 23:447-456.

13. Dandona P, Aljada A, Bandyopadhyay A: Inflammation: the link between insulin resistance, obesity and diabetes. Trends Immunol 2004, 25:4-7.

14. McGarry JD: Banting lecture 200 I: dysregulation of fatty acid metabolism in the etiology of type 2 diabetes. Diabetes 2002, 51:7-18.

15. Slawik $M$, Vidal-Puig AJ: Lipotoxicity, overnutrition and energy metabolism in aging. Ageing Res Rev 2006, 5: 144- 164.

16. Boden G, Chen X, Rosner J, Barton M: Effects of a 48-h fat infusion on insulin secretion and glucose utilization. Diabetes 1995, 44:1239-1242. 
17. Brechtel K, Dahl DB, Machann J, Bachmann OP, Wenzel I, Maier T, Claussen CD, Haring HU, Jacob S, Schick F: Fast elevation of the intramyocellular lipid content in the presence of circulating free fatty acids and hyperinsulinemia: a dynamic IH-MRS study. Magn Reson Med 200I, 45: I79-I83.

18. Kelley DE, Mintun MA, Watkins SC, Simoneau JA, Jadali F, Fredrickson A, Beattie J, Theriault R: The effect of non-insulin-dependent diabetes mellitus and obesity on glucose transport and phosphorylation in skeletal muscle. J Clin Invest 1996, 97:2705-27I3.

19. Roden M, Price TB, Perseghin G, Petersen KF, Rothman DL, Cline GW, Shulman Gl: Mechanism of free fatty acid-induced insulin resistance in humans. J Clin Invest 1996, 97:2859-2865.

20. Permana PA, Menge C, Reaven PD: Macrophage-secreted factors induce adipocyte inflammation and insulin resistance. Biochem Biophys Res Commun 2006, 34I:507-5I4.

21. Weisberg SP, McCann D, Desai M, Rosenbaum M, Leibel RL, Ferrante AW Jr: Obesity is associated with macrophage accumulation in adipose tissue. J Clin Invest 2003, I I 2: I796- I808.

22. Patiag D, Gray S, Idris I, Donnelly R: Effects of tumour necrosis factor-alpha and inhibition of protein kinase $C$ on glucose uptake in L6 myoblasts. Clin Sci (Lond) 2000, 99:303-307.

23. Plomgaard P, Bouzakri K, Krogh-Madsen R, Mittendorfer B, Zierath $J R$, Pedersen BK: Tumor necrosis factor-alpha induces skeletal muscle insulin resistance in healthy human subjects via inhibition of Akt substrate 160 phosphorylation. Diabetes 2005, 54:2939-2945.

24. Ranganathan S, Davidson MB: Effect of tumor necrosis factoralpha on basal and insulin-stimulated glucose transport in cultured muscle and fat cells. Metabolism 1996, 45:1089-1094.

25. Ebbeling CB, Leidig MM, Sinclair KB, Hangen JP, Ludwig DS: A reduced-glycemic load diet in the treatment of adolescent obesity. Arch Pediatr Adolesc Med 2003, I 57:773-779.

26. Ebbeling CB, Leidig MM, Sinclair KB, Seger-Shippee LG, Feldman HA, Ludwig DS: Effects of an ad libitum low-glycemic load diet on cardiovascular disease risk factors in obese young adults. $\mathrm{Am}$ J Clin Nutr 2005, 81:976-982.

27. Maki KC, Rains TM, Kaden VN, Raneri KR, Davidson MH: Effects of a reduced-glycemic-load diet on body weight, body composition, and cardiovascular disease risk markers in overweight and obese adults. Am / Clin Nutr 2007, 85:724-734.

28. Sloth B, Krog-Mikkelsen I, Flint A, Tetens I, Bjorck I, Vinoy S, Elmstahl $H$, Astrup $A$, Lang $V$, Raben $A$ : No difference in body weight decrease between a low-glycemic-index and a high-glycemicindex diet but reduced LDL cholesterol after 10 -wk ad libitum intake of the low-glycemic-index diet. Am J Clin Nutr 2004, 80:337-347.

29. Giugliano D, Esposito K: Mediterranean diet and metabolic diseases. Curr Opin Lipidol 2008, 19:63-68.

30. Executive Summary of The Third Report of The National Cholesterol Education Program (NCEP) Expert Panel on Detection, Evaluation, And Treatment of High Blood Cholesterol In Adults (Adult Treatment Panel III). Jama 200I, 285:2486-2497.

3I. Grundy SM, Cleeman JI, Daniels SR, Donato KA, Eckel RH, Franklin BA, Gordon DJ, Krauss RM, Savage PJ, Smith SC Jr, Spertus JA, Costa $F$ : Diagnosis and management of the metabolic syndrome: an American Heart Association/National Heart, Lung, and Blood Institute Scientific Statement. Circulation 2005, I | 2:2735-2752.

32. Giugliano D, Ceriello A, Esposito K: Are there specific treatments for the metabolic syndrome? Am J Clin Nutr 2008 , 87:8-II.

33. O'Keefe JH, Gheewala NM, O'Keefe JO: Dietary strategies for improving post-prandial glucose, lipids, inflammation, and cardiovascular health. I Am Coll Cardiol 2008, 5 I:249-255.

34. Lassila M, Allen TJ, Cao Z, Thallas V, Jandeleit-Dahm KA, Candido R, Cooper ME: Imatinib attenuates diabetes-associated atherosclerosis. Arterioscler Thromb Vasc Biol 2004, 24:935-942.

35. Lin JK: Molecular targets of curcumin. Adv Exp Med Biol 2007, 595:227-243.

36. Si H, Liu D: Phytochemical genistein in the regulation of vascular function: new insights. Curr Med Chem 2007, I 4:258I-2589.

37. Lukaczer D, Liska DJ, Lerman RH, Darland G, Schiltz B, Tripp M, Bland JS: Effect of a low glycemic index diet with soy protein and phytosterols on CVD risk factors in postmenopausal women. Nutrition 2006, 22: I04- II3.
38. Riccardi G, Clemente G, Giacco R: Glycemic index of local foods and diets: the Mediterranean experience. Nutr Rev 2003, 6 I :S56-60.

39. Foster-Powell K, Holt SH, Brand-Miller JC: International table of glycemic index and glycemic load values: 2002. Am J Clin Nutr 2002, 76:5-56.

40. Ware JE Jr, Sherbourne CD: The MOS 36-item short-form health survey (SF-36). I. Conceptual framework and item selection. Med Care 1992, 30:473-483.

4I. White MA, Whisenhunt BL, Williamson DA, Greenway FL, Netemeyer RG: Development and validation of the food-craving inventory. Obes Res 2002, 10:107-114.

42. Grundy SM, Pasternak R, Greenland P, Smith S Jr, Fuster V: AHA/ ACC scientific statement: Assessment of cardiovascular risk by use of multiple-risk-factor assessment equations: a statement for healthcare professionals from the American Heart Association and the American College of Cardiology. J Am Coll Cardiol 1999, 34:1348-I359.

43. Nauck M, Warnick GR, Rifai N: Methods for measurement of LDL-cholesterol: a critical assessment of direct measurement by homogeneous assays versus calculation. Clin Chem 2002, 48:236-254.

44. Maki KC, Galant R, Davidson MH: Non-high-density lipoprotein cholesterol: the forgotten therapeutic target. Am J Cardiol 2005, 96:59K-64K.

45. Anderson RA: Chromium and polyphenols from cinnamon improve insulin sensitivity. Proc Nutr Soc 2008, 67:48-53.

46. Heilbronn LK, Noakes M, Clifton PM: The effect of high- and lowglycemic index energy restricted diets on plasma lipid and glucose profiles in type 2 diabetic subjects with varying glycemic control. J Am Coll Nutr 2002, 2 I: I 20- 127.

47. Noakes M, Foster PR, Keogh JB, Clifton PM: Meal replacements are as effective as structured weight-loss diets for treating obesity in adults with features of metabolic syndrome. J Nutr 2004, I34: 1894-1899.

48. De Keukeleire D: Fundamentals of beer and hop chemistry. Química Nova 2000, 23: 108-II 2.

49. De Keukeleire D, De Cooman L, Rong H, Heyerick A, Kalita J, Milligan SR: Functional properties of hop polyphenols. Basic Life Sci 1999, 66:739-760.

50. Abd el Nabi OM, Reisinger EC, Reinthaler FF, Still F, Eibel U, Krejs G]: Antimicrobial activity of Acacia nilotica (L.) Willd. ex Del. var. nilotica (Mimosaceae). J Ethnopharmacol 1992, 37:77-79.

51. Al-Mustafa ZH, Dafallah AA: A study on the toxicology of Acacia nilotica. Am J Chin Med 2000, 28:123-129.

52. Kaur K, Arora S, Hawthorne ME, Kaur S, Kumar S, Mehta RG: A correlative study on antimutagenic and chemopreventive activity of Acacia auriculiformis A. Cunn. and Acacia nilotica (L.) Willd. Ex Del. Drug Chem Toxicol 2002, 25:39-64.

53. TR N: A Biology of Acacias. Melbourne, Oxford University Press; 1984.

54. Shimura M, Hasumi A, Minato T, Hosono M, Miura Y, Mizutani S, Kondo K, Oikawa S, Yoshida A: Isohumulones modulate blood lipid status through the activation of PPAR alpha. Biochim Biophys Acta 2005, I 736:5I-60.

55. Yajima H, Ikeshima E, Shiraki M, Kanaya T, Fujiwara D, Odai H, Tsuboyama-Kasaoka N, Ezaki O, Oikawa S, Kondo K: Isohumulones, bitter acids derived from hops, activate both peroxisome proliferator-activated receptor alpha and gamma and reduce insulin resistance. J Biol Chem 2004, 279:33456-33462.

56. Jenkins DJ, Wolever TM, Kalmusky J, Guidici S, Giordano C, Patten R Wong GS, Bird JN, Hall M, Buckley G, et al.: Low-glycemic index diet in hyperlipidemia: use of traditional starchy foods. $A m \mathrm{~J}$ Clin Nutr 1987, 46:66-7I.

57. Esposito K, Marfella R, Ciotola M, Di Palo C, Giugliano F, Giugliano G, D'Armiento M, D'Andrea F, Giugliano D: Effect of a mediterranean-style diet on endothelial dysfunction and markers of vascular inflammation in the metabolic syndrome: a randomized trial. Jama 2004, 292: |440-|446.

58. Orchard TJ, Temprosa M, Goldberg R, Haffner S, Ratner R, Marcovina $S$, Fowler S: The effect of metformin and intensive lifestyle intervention on the metabolic syndrome: the Diabetes Prevention Program randomized trial. Ann Intern Med 2005, |42:6I I-619.

59. Ghandehari H, Kamal-Bahl S, Wong ND: Prevalence and extent of dyslipidemia and recommended lipid levels in US adults with 
and without cardiovascular comorbidities: the National Health and Nutrition Examination Survey 2003-2004. Am Heart J 2008, 156:1 12-119.

60. Cui Y, Blumenthal RS, Flaws JA, Whiteman MK, Langenberg P, Bachorik PS, Bush TL: Non-high-density lipoprotein cholesterol level as a predictor of cardiovascular disease mortality. Arch Intern Med 2001, 161:1413-1419.

61. Lu W, Resnick HE, Jablonski KA, Jones KL, Jain AK, Howard WJ, Robbins DC, Howard BV: Non-HDL cholesterol as a predictor of cardiovascular disease in type 2 diabetes: the strong heart study. Diabetes Care 2003, 26:16-23.

62. Shai I, Rimm EB, Hankinson SE, Curhan G, Manson JE, Rifai N, Stampfer MJ, Ma J: Multivariate assessment of lipid parameters as predictors of coronary heart disease among postmenopausal women: potential implications for clinical guidelines. Circulation 2004, I I 0:2824-2830.

63. Grundy SM, Cleeman JI, Merz CN, Brewer HB Jr, Clark LT, Hunninghake DB, Pasternak RC, Smith SC Jr, Stone NJ: Implications of recent clinical trials for the National Cholesterol Education Program Adult Treatment Panel III guidelines. Circulation 2004, I I 0:227-239.

64. Chan DC, Watts GF: Apolipoproteins as markers and managers of coronary risk. Qjm 2006, 99:277-287.

65. Hankey GJ: Potential new risk factors for ischemic stroke: what is their potential? Stroke 2006, 37:218I-2I88.

66. Hoffstedt J, Forster D, Lofgren P: Impaired subcutaneous adipocyte lipogenesis is associated with systemic insulin resistance and increased apolipoprotein B/AI ratio in men and women. J Intern Med 2007, 262:13|-139.

67. Ingelsson E, Schaefer EJ, Contois JH, McNamara JR, Sullivan L, Keyes MJ, Pencina MJ, Schoonmaker C, Wilson PW, D'Agostino RB, Vasan RS: Clinical utility of different lipid measures for prediction of coronary heart disease in men and women. Jama 2007, 298:776-785.

68. Onat A, Can G, Hergenc G, Yazici M, Karabulut A, Albayrak S: Serum apolipoprotein B predicts dyslipidemia, metabolic syndrome and, in women, hypertension and diabetes, independent of markers of central obesity and inflammation. Int J Obes (Lond) 2007, 3 I: I I I 9- I I 25.

69. Rasouli M, Kiasari AM: Interactions of serum hsCRP with apoB apoB/AI ratio and some components of metabolic syndrome amplify the predictive values for coronary artery disease. Clin Biochem 2006, 39:97I-977.

70. Sierra-Johnson J, Somers VK, Kuniyoshi FH, Garza CA, Isley WL, Gami AS, Lopez-Jimenez F: Comparison of apolipoprotein-B/ apolipoprotein-Al in subjects with versus without the metabolic syndrome. Am J Cardiol 2006, 98:1369-1373.

7I. Walldius G, Jungner I: The apoB/apoA-I ratio: a strong, new risk factor for cardiovascular disease and a target for lipid-lowering therapy - a review of the evidence. J Intern Med 2006, 259:493-519.

72. Yusuf S, Hawken S, Ounpuu S, Dans T, Avezum A, Lanas F, McQueen $M$, Budaj A, Pais $P$, Varigos J, Lisheng L: Effect of potentially modifiable risk factors associated with myocardial infarction in 52 countries (the INTERHEART study): case-control study. Lancet 2004, 364:937-952.
Publish with Bio Med Central and every scientist can read your work free of charge

"BioMed Central will be the most significant development for disseminating the results of biomedical research in our lifetime. "

Sir Paul Nurse, Cancer Research UK

Your research papers will be:

- available free of charge to the entire biomedical community

- peer reviewed and published immediately upon acceptance

- cited in PubMed and archived on PubMed Central

- yours - you keep the copyright

Submit your manuscript here:

http://www.biomedcentral.com/info/publishing_adv.asp
BiolMedcentral 